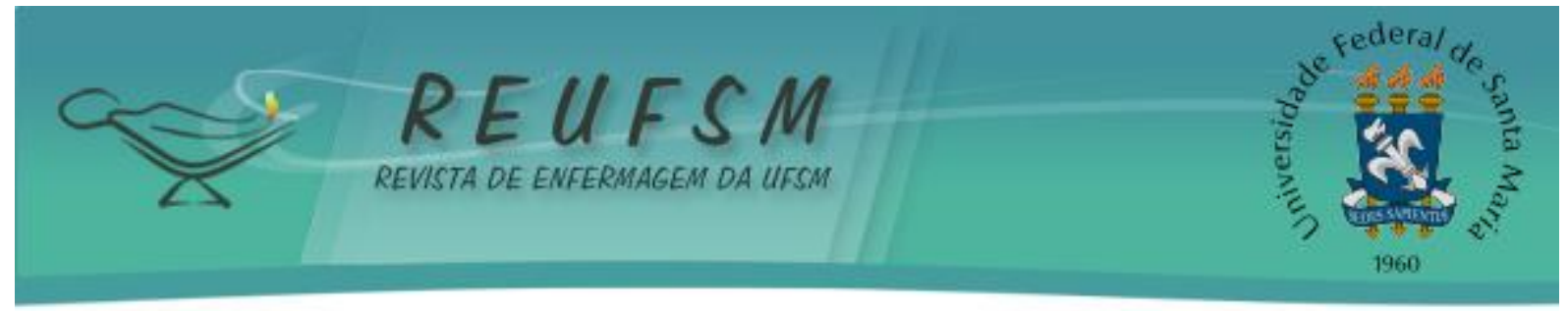

ARTIGO ORIGINAL

\title{
“VIREI UM MENDIGO”: VIVÊNCIAS DE EX-MORADORES DE RUA ACOLHIDOS POR UMA INSTITUIÇÃO CONFESSIONAL BRASILEIRA
}

\section{“I BECAME A BEGGAR": LIFE EXPERIENCE REPORTS OF FORMER HOMELESS PEOPLE SHELTERED IN A BRAZILIAN CONFESSIONAL INSTITUTION}

\section{“ME TORNÉ UN MENDIGO": VIVENCIAS DE ANTIGUOS SIN TECHO ACOGIDOS EN UNA INSTITUCIÓN CONFESIONAL BRASILEÑA}

\author{
Milene Pescatori Packer ${ }^{1}$ \\ Rosângela Higa ${ }^{2}$ \\ Cássia Regina Rodrigues ${ }^{3}$ \\ Claudinei José Gomes Campos ${ }^{4}$ \\ Egberto Ribeiro Turato ${ }^{5}$
}

\section{Doi: $10.5902 / 2179769212964$}

RESUMO: Objetivo: analisar as vivências de ex-moradores de rua usuários de álcool acolhidos por uma Instituição Confessional. Método: fundamentado no método clínicoqualitativo, de agosto de 2007 a maio de 2008 foram realizadas entrevistas semiestruturadas com moradores de uma organização filantrópica do interior do Estado de São Paulo. O critério de saturação definiu a amostra de oito participantes. Resultados: três categorias foram constituídas com a técnica de análise de conteúdo temática: Você fica com vergonha: expressa tendência ao isolamento ou formação de grupos; Virei um mendigo: apresenta a ruptura da vida social e perda da identidade; $O$ que passou não volta mais: demonstra a tentativa de livrar-se da imagem de si mesmo, negação social e identificação com os novos papéis. Conclusão: para sobreviver, o ex-morador nega elementos centrais da sua identidade e vivencia a reconstrução da nova identidade. Para retornar ao antigo lar/sociedade necessita reconfigurar a identidade perdida.

Descritores: Pesquisa qualitativa; População em risco; Psicologia social; Comunidades vulneráveis.

ABSTRACT: Aim: to analyze the life experiences of former homeless alcohol users sheltered in a Confessional Institution. Method: the study is based on the clinicalqualitative method. From August 2007 to May 2008, semi-structured interviews were carried out with residents of a philanthropic organization in the state of São Paulo. The saturation criterion defined a sample of eight participants. Results: three categories were composed through the content analysis technique: You get embarrassed: expresses tendency to isolation or forming groups; I became a beggar: shows the breakdown of

\footnotetext{
${ }^{1}$ Terapeuta Ocupacional. Mestre em Ciências Médicas - Faculdade de Ciências Médicas (FCM) Universidade Estadual de Campinas (UNICAMP). CAPS ad III Indaiatuba. Indaiatuba - SP - Brasil. E-mail: packer_mi@hotmail.com

${ }^{2}$ Enfermeira. Doutora pelo Departamento de Tocoginecologia - FCM/UNICAMP. Assistente Técnico de Direção Divisão de Enfermagem do Hospital da Mulher Prof. Dr. José Aristodemo Pinotti - CAISM/UNICAMP. Campinas SP - Brasil. E-mail: rosangelahiga@bol.com.br

${ }^{3}$ Psicóloga. Doutora em Saúde Mental pela Faculdade de Medicina da USP Ribeirão Preto. Professora Adjunta do Departamento de Medicina do Centro de Ciências Biológicas e da Saúde da Universidade Federal de São Carlos. São Carlos - SP - Brasil. E-mail: cassiavarga@terra.com.br

${ }^{4}$ Enfermeiro. Doutor em Ciências Médicas - FCM/UNICAMP. Professor Doutor da Faculdade de Enfermagem da UNICAMP. Campinas - SP - Brasil. E-mail: ccampos@unicamp.br

${ }^{5}$ Psiquiatra. Professor Titular em Prática de Ciências. Líder do LPQC - Laboratório de Psicologia Médica e Psiquiatria FCM/UNICAMP. Campinas - SP - Brasil. E-mail: erturato@uol.com.br
} 


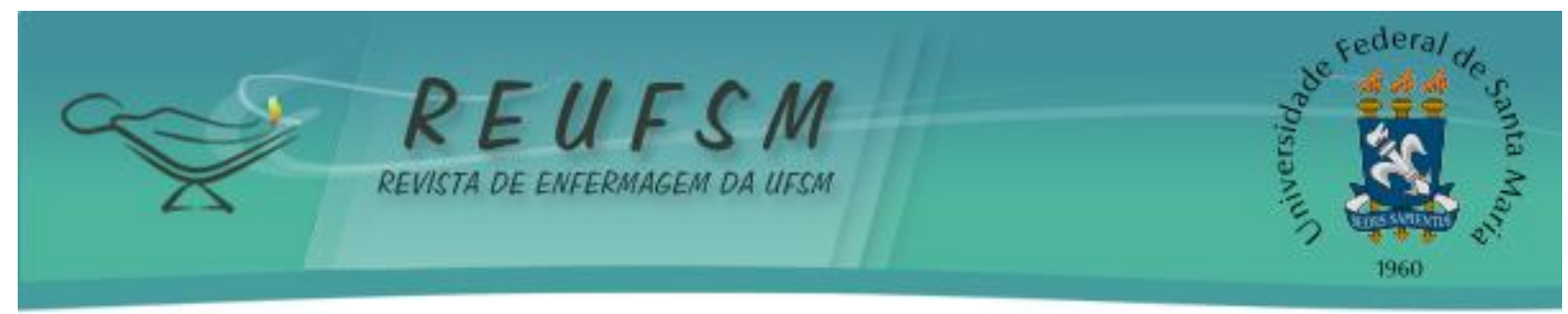

social life and loss of identity; The past will not return: demonstrates an attempt to get rid of their self-image, social denial and identification with the new roles. Conclusion: to survive, the former homeless person denies central elements of their identity and experiences the reconstruction of a new identity. In order to return to the former home/society, it is necessary to recompose the lost identity.

Descriptors: Qualitative research; Population at risk; Psychology social; Vulnerable groups.

RESUMEN: Objetivo: analizar las experiencias de vida de antiguos sin-techo alcoholicos acogidos en institución confesional. Método: basado en el método clínico-cualitativo, entre Agosto/2007 y mayo/2008 se realizaron entrevistas semi-estructuradas con residentes de una organización filantrópica del estado de São Paulo (Brasil). El criterio de satuaração definió la muestra de ocho participantes. Resultados: la técnica de análisis de contenido constituyó tres categorías: "Estás avergonzado": expresa una tendencia al aislamiento o formación de grupos; "Me torné un mendigo": presenta una ruptura de la vida social con pérdida de identidad; «El pasado no volverá »: muestra intento de deshacerse de la imagen de sí mismo, negación social e identificación con los nuevos roles. Conclusión: para sobrevivir, ellos niegam elementos centrales de su identidad y experimentan la reconstrucción de la nueva identidad. Para volver al antiguo hogar/sociedad necesita reconfigurar la identidad pérdida.

Descriptores: Investigación cualitativa; Población en riesgo; Psicología social; Comunidades vulnerables.

\section{INTRODUÇÃO}

Durante as últimas décadas tem sido observado o crescimento da população que vive na rua, fruto de uma sociedade globalizada, desigual e com acentuada exclusão social. ${ }^{1-2} 0$ rompimento dos vínculos familiares é motivado por situações de pobreza, alcoolismo e conflitos, as quais são consideradas fatores que desencadeiam a ida para as ruas. ${ }^{3}$

O termo "morador de rua" define aquele indivíduo que não reside em local fixo (residência) e que pernoita, de forma permanente ou temporária, em albergues, áreas públicas da cidade, casas abandonadas, entre outras. Além disso, podem utilizar os logradouros para atividades que geram renda para sua sobrevivência. ${ }^{4}$

Segundo estudo do Ministério do Desenvolvimento Social e de Combate à Fome, realizado em 71 municípios brasileiros, 31.922 adultos estão sem residência, destes, 70,9\% exercem alguma atividade remunerada, especialmente na economia informal, e $69,6 \%$ dormem nas ruas, sendo que $22,1 \%$ procuram abrigos e $8,3 \%$ se deslocam entre ambos os espaços. ${ }^{5}$

Dada à diversidade de características que essas pessoas apresentam, muitas são as denominações utilizadas para essa população, entre elas: mendigos, trecheiros ou moradores de rua ${ }^{6}$. Vivem expostas a condições precárias, apresentando dificuldades para o acesso aos direitos básicos de cidadania, como o trabalho, habitação, alimentação, saneamento e saúde. ${ }^{7}$

Estudo realizado em instituições de acolhimento mostrou que, em relação à população em geral, a prevalência do HIV foi desproporcionalmente elevada em moradores de rua de São Paulo. Evidenciando que os processos de exclusão social aumentam a vulnerabilidade e propiciam maior exposição ao HIV, principalmente entre homossexuais, mulheres e jovens. ${ }^{8}$

Mesmo habitando ambientes insalubres e desprovidos de condições adequadas para uma vida saudável, para alguns moradores viver nas ruas significa liberdade. Contudo, para outros, viver com saúde está associado às normas e regras dos albergues, uma vez que são nesses espaços que se privam do consumo de álcool e outras drogas ilícitas. Tais contradições 


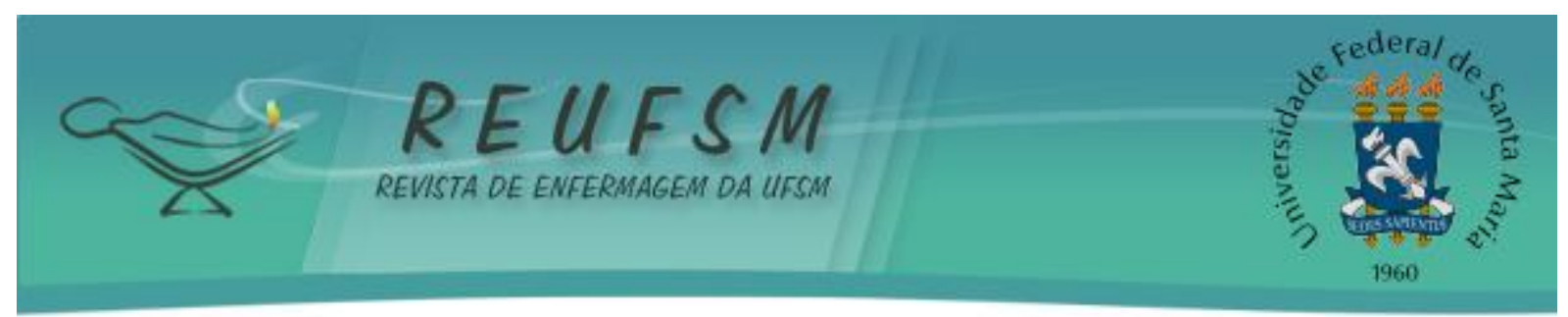

levam estes indivíduos a vivenciarem um processo de organização e reorganização de suas identidades, as quais possibilitam relações e interações do ser e estar nas ruas. ${ }^{9}$

Estudos da Fundação Instituto de Pesquisas Econômicas (FIPE) destacam que essas pessoas partilham inúmeras características, como: pobreza, trajetórias de vida cheias de fracassos e desamparo institucional. Por não terem casa, diariamente buscam alimentos, abrigo, dinheiro, bebida, remédios e segurança, como solução para sobrevivência. ${ }^{10}$

Contudo, a ação humana do indivíduo e do grupo, variam conforme a inserção ambiental e o tipo de organização em que se encontram. É possível postular que é na sociedade ou comunidade em que vivemos que formamos ou constituímos nossas identidades, ou seja, a forma como somos e nos vemos. Tomando como premissa que a identidade é composta por uma união de crenças, valores e hábitos, que orientam as ações dos indivíduos dentro de um contexto preexistente. ${ }^{11}$

Deste modo, uma pessoa poderá ter aspectos de sua identidade alterados dependendo de mudanças sócio-ambientais. A identidade é marcada por significados simbólicos; é construída na relação com a percepção das significações atribuídas por si e pelos outros possibilitando um compartilhamento. ${ }^{12}$ Por meio desse compartilhar que, no contexto organizacional, as identidades se reconstroem segundo valores e concepções desenvolvidos ao lidar com conflitos e problemas. ${ }^{11}$

Assim, compreender os significados dos sentimentos e das diversas formas de vida experimentadas pelos ex-moradores de rua, como o caminho que o levou até lá e a tentativa de retorno à antiga sociedade, poderá subsidiar os profissionais da saúde nas reflexões sobre as necessidades físicas, psíquicas e socioculturais. Estas servirão como subsídio para ações humanizadas do cuidado aos moradores de rua que buscam o retorno e, além disso, contribuirão para o embasamento de discussões sobre as estratégias que possam auxiliar na prevenção da ida às ruas de outras pessoas.

Perguntando sobre quais seriam as características que essas pessoas, ao saírem de suas casas reinventaram para sobreviver e não ser mais quem eram, o objetivo desse estudo teve como perspectiva analisar as vivências de ex-moradores de rua usuários de álcool acolhidos por uma Instituição Confessional.

\section{MÉTODO}

A pesquisa se alicerçou nos pressupostos do método Clínico-Qualitativo caracterizado como um enquadre específico das metodologias qualitativas, o qual permite que os sentimentos e as vivências humanas sejam analisados e discutidos por meio da escuta das expressões e entonações afetivas, colocando em foco os aspectos emocionais presentes nas narrativas dos entrevistados. ${ }^{13}$

O enfoque no percurso do processo saúde-doença tem como finalidade explorar os elementos que possam ampliar a compreensão dos pilares que compõe os adoecimentos das pessoas, possibilitando que ações possam ser desenvolvidas para a melhora da qualidade de vida da população estudada.

0 estudo foi realizado em duas Instituições Confessionais de acolhimento para moradores de rua do sexo masculino, do interior do Estado de São Paulo. Nessas instituições alguns moradores saíam para o trabalho e outros que não tinham essa permissão por não terem condições para desenvolver qualquer atividade.

Fundada em 1994, mantida por amigos e benfeitores, as Instituições Confessionais Católicas se inspiram nos ensinamentos de São Francisco de Assis, em seu zelo eucarístico e amor aos pobres. Têm como objetivo abrigar e aliviar os sofrimentos de moradores de rua, e são encontradas em dezesseis estados brasileiros e três no exterior. Embora tenham os mesmos objetivos, cada instituição tem características próprias, ou seja, entre as que 


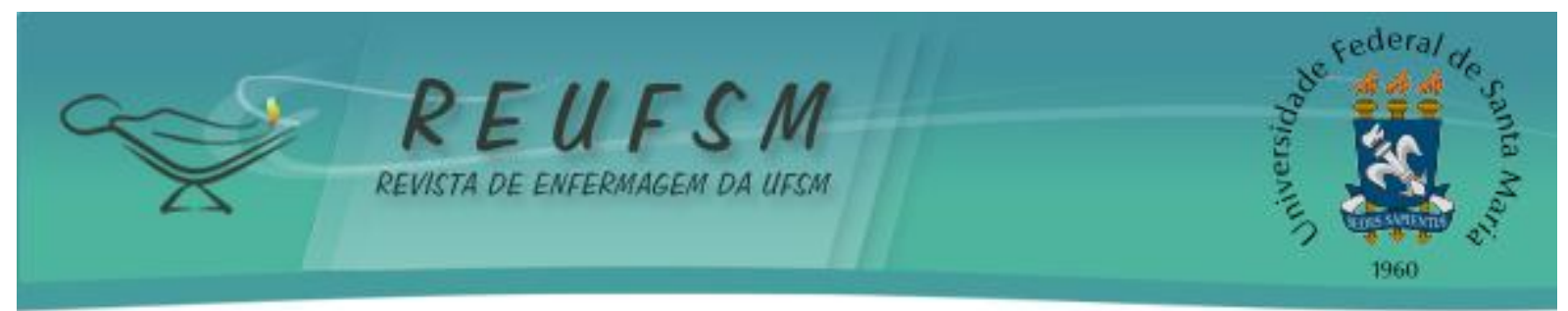

acolhem os moradores de rua, há instituições somente para pernoite e outras que não permitem a saída dos moradores, exceto se estiverem acompanhados. Contudo, todo morador tem liberdade para deixar a casa no momento que desejar, porém, necessita seguir as normas e disciplinas para viverem na instituição. ${ }^{14}$

Os participantes para o estudo foram selecionados respeitando os seguintes critérios de inclusão: ter mais de 18 anos; ser morador da Instituição; ter morado nas ruas; ter sido ou ser usuário de bebida alcoólica; e não apresentar transtornos mentais depois de aplicado o Self Reporting Questionnaire (SRQ 20). ${ }^{15}$ A escolha do SRQ 20 deu-se por tratar de um instrumento de fácil e rápida aplicação e indica possíveis transtornos psiquiátricos que poderiam comprometer o resultado da pesquisa. Foram excluídos do estudo os participantes com dificuldade na dicção ou comprometimento cognitivo, uma vez que dificultou a transcrição e a fidedignidade dos dados.

A coleta dos dados ocorreu no período de agosto de 2007 a maio de 2008, sendo realizadas 15 entrevistas. As quatro primeiras foram para o processo de aculturação e adequação do roteiro de coleta dos dados. Três foram eliminadas por terem apresentado pelo menos um critério de exclusão. Oito entrevistas foram válidas para este estudo utilizando o critério de saturação das informações colhidas ${ }^{16}$ para o fechamento da amostra.

Por meio da entrevista semiestruturada de questões abertas e utilizando a questão disparadora: "Conte a história da sua vida", investigou-se o conjunto de vivências mencionadas sobre como a pessoa estava se vendo, o que sentia por si própria, sua vida atual, as dificuldades de se viver fora da moradia perdida, os motivos que o levaram a morar nas ruas e as expectativas sobre si e a própria vida.

Os dados transcritos foram analisados à luz da técnica de análise de conteúdo temática, a qual consiste:

"Descobrir os núcleos de sentido que compõem uma comunicação, cuja presença ou frequência signifiquem alguma coisa para o objeto analítico visado [...] Para uma análise de significados, a presença de determinados temas denota estruturas de relevância, valores de referência e modelos de comportamento presentes ou subjacentes no discurso."17:316

Com o desdobramento das etapas, como a leitura flutuante, tratamento e interpretação dos resultados, os núcleos de sentido foram configurados em três categorias: Você fica com vergonha; Virei um mendigo; e $O$ que passou não volta mais. As categorias foram validadas pelos pares do Laboratório de Pesquisa Clínico-Qualitativo da Faculdade de Ciências Médicas da Universidade Estadual de Campinas (FCM/UNICAMP).

O referencial teórico para a interpretação dos achados foi a perspectiva psicanalítica/psicodinâmica que se caracteriza por um conjunto de princípios básicos advindos da psicanálise, inaugurada por Freud: “Inconsciente dinâmico, uma lente desenvolvimental para enxergar a experiência adulta e o determinismo psíquico."15:14

0 referencial também destaca que:

"Este estabelece que a nossa experiência interna, nossos comportamentos, nossa escolha de parceiros, nossas decisões de carreira e até nossos passatempos são moldados por forças inconscientes." $18: 16$ 


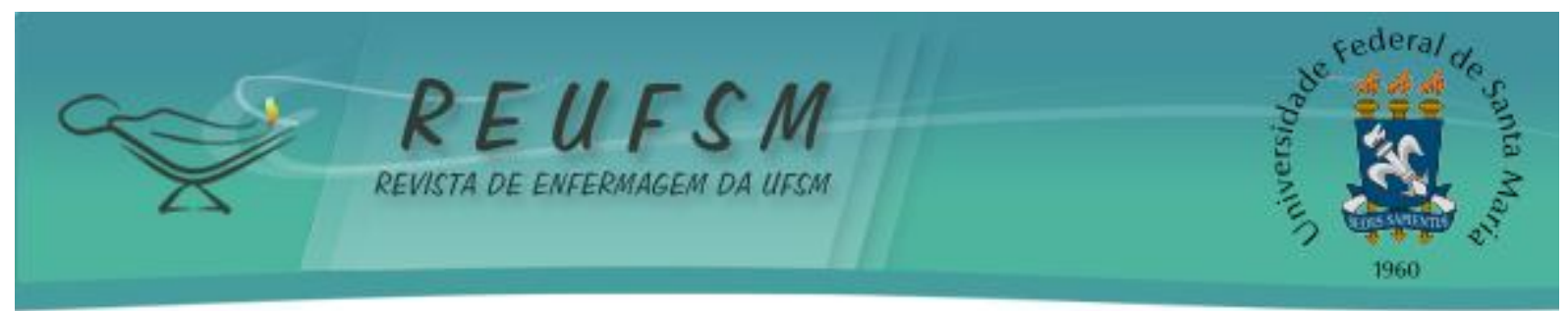

A pesquisa foi aprovada pelo Comitê de Ética em Pesquisa da Universidade Estadual de Campinas (UNICAMP) em 23 de Outubro de 2007, parecer $n^{\circ}$ 621/2006. Todos os participantes assinaram o Termo de Consentimento Livre e Esclarecido (TCLE).

\section{RESULTADOS E DISCUSSÃO}

A amostra foi composta por ex-moradores de rua do sexo masculino na faixa etária de 45 a 62 anos, com tempo de estadia na instituição variando de um mês a 13 anos.

Os depoimentos sobre as experiências e emoções a partir da saída da sociedade e ida para as ruas, desperta sentimentos como a vergonha e o não reconhecimento de si próprio. Por conseguinte, nota-se que essas pessoas temem falar do passado para não lembrarem quem já foram um dia. Esse processo de negação fez com que a identidade atual fosse associada à sua nova vida ou à nova condição de alguém sem moradia fixa.

\section{Você fica com vergonha}

Gradativamente, o indivíduo abandona hábitos, costumes, conceitos e preconceitos, para pouco a pouco vivenciar e adquirir um novo entendimento do espaço em que habita e, por que não dizer, da nova vida. Em sua fala, o entrevistado sente vergonha pela situação física em que se encontra: sujo e maltrapilho:

O problema da rua é esse, você fica dez, quinze dias sem tomar banho, entendeu? Daí que você fica com vergonha de chegar $e$ encostar-se a uma pessoa pra conversar, porque nem você mesmo está aguentando seu próprio cheiro. (E8)

Condições de vida que a ida para as ruas impõe e gera sentimentos de vergonha. Para sobreviver esquecem seus próprios princípios, valores, crenças e singularidades.

A literatura sobre o tema destaca que os sentimentos de vergonha e humilhação fazem com que os moradores de rua se afastem ainda mais do contato com as pessoas e resulta numa tendência ao isolamento ou formação de grupos que thes confiram uma identidade estável. ${ }^{19}$ Aponta ainda, que essa população demonstra ser sensível à possibilidade de um vergonhoso descrédito. ${ }^{20}$

Assim sendo, alguns deles optam por deixar sua dignidade e preceitos anteriores e se submetem a pedir dinheiro e/ou comida mesmo diante das dificuldades que aquela situação lhes acarreta, e dos sentimentos dolorosos que passam a cultivar pela condição a que estão submetidos:

Foi difícil para eu acostumar, foi difícil. Eu tinha vergonha de pedir um centavo. Chegava, baixava a cabeça [...] Você não tem muita saída, você pede. Ah! Quer saber de uma coisa, vou perder essa vergonha, deixar pra lá. (E4)

Esses oito meses que fiquei na rua não foram fáceis. Eu tenho vergonha de pedir porque peço para dez pessoas, das dez uma me dá, outras me ofendem, xingam. (E2)

Independente da escolha ou não por arrecadação de dinheiro, de uma forma ou de outra eles conseguem sobreviver. A mendicância não é bem vista pela população e, essa 


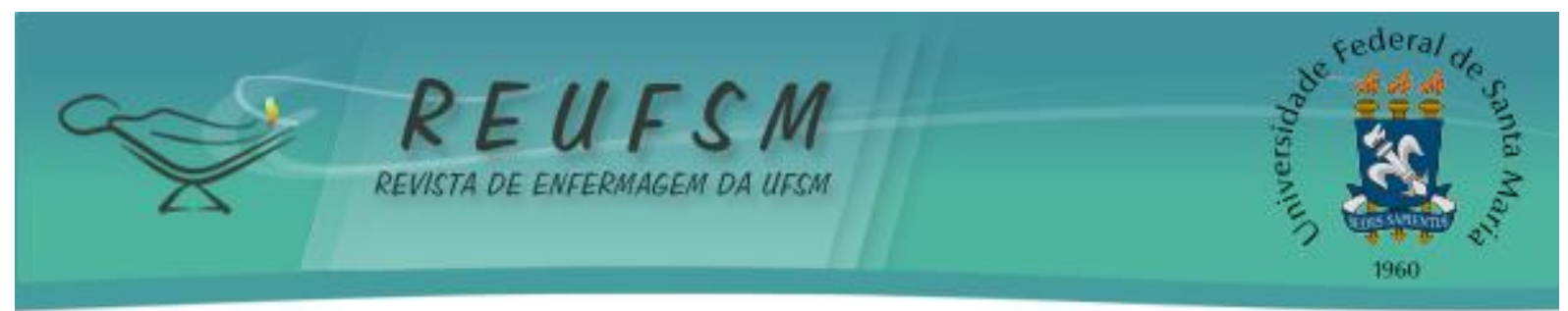

avaliação das pessoas é percebida pelo andarilho, como uma situação constrangedora. 0 ato de pedir os humilha, entretanto, prevalece a necessidade de sobrevivência.

Nos discursos presentes nas entrevistas é comum o relato das dificuldades de se adaptarem à rotina, as regras, normas e valores da nova sociedade que agora pertencem. Quando são perguntados sobre o que se lembram do período em que ficaram na rua, dizem:

É só coisas desagradáveis. [...] A gente se encontrava no bar, pra comprar um salgado, mas o dinheiro pra comprar um salgado (dizia ele) eu não tenho, se quer uma pinga é de copo cheio [...] metade das vezes eu não concordei e metade [...] das vezes pra suprir um vaco no estômago [...] eu bebia. (E1)

Quando você chega na rua tudo fica meio estranho, não é acostumado. Ai vai indo, depois acostuma. (E7)

Observa-se pelos achados desse estudo que muitos moradores sentem-se, mesmo após anos de rua, envergonhados de "encharcar" - nome que eles referiam para o ato de beber em demasia - mas, com o passar do tempo se adaptam à rotina e reconstroem a identidade baseada em novos hábitos, crenças, valores e amigos/família. É o início de uma nova identidade.

Considera-se pelos dados coletados que a exclusão social seja um processo marcante em suas vidas que interfere na constituição da sua identidade e reduz a perspectiva de sair da situação de morar na rua. A literatura sobre o tema considera que a mudança do contexto social a que uma pessoa pertence acontece gradativamente ${ }^{10}$ e que os indivíduos que moram na rua podem vivenciar a "mutilação" de suas vidas de diferentes formas: através do sofrimento ético-político; da "negação" imposta socialmente; da "dor" que surge da situação social de ser tratado como inferior, subalterno, sem valor, apêndice inútil da sociedade. ${ }^{19}$

Segundo alguns autores, ${ }^{20-21}$ o morador de rua se considera numa prisão difícil de sair, pois tanto as relações desenvolvidas quanto o uso de drogas, o estado de abandono e de exclusão social, são fatores que os empurram, cada vez mais, para as sarjetas.

Embora um estudo relate que para alguns moradores a rua representa liberdade e paz, ter amigos, não ter horários, regras e rotinas, ${ }^{9}$ nota-se que a vulnerabilidade dessa população ocasiona fragilidades, exposição à discriminação, à violência e a desumanização.

\section{Virei um mendigo}

A ruptura do papel de indivíduo na sociedade, algumas vezes marcada pelo consumo do álcool, mostra claramente a vivência do processo de perdas, em especial as de ordem afetiva:

Quando você entra na bebida, primeiramente, o que você perde é a família; segundo, é o emprego; terceiro, a sociedade já te discrimina, daí você perde sua dignidade; o que vai sobrar pra você é a rua [...] porque a rua é o lugar de pessoas exclusas [...] infelizmente, é a realidade. (E8)

A degeneração, o rompimento dos vínculos familiares, social e profissional, leva ao detrimento e provoca a fragmentação da identidade enquanto cidadão; e direciona a vivência em um ambiente carregado de estresse, violência, hostilidade e solidão. Estes 


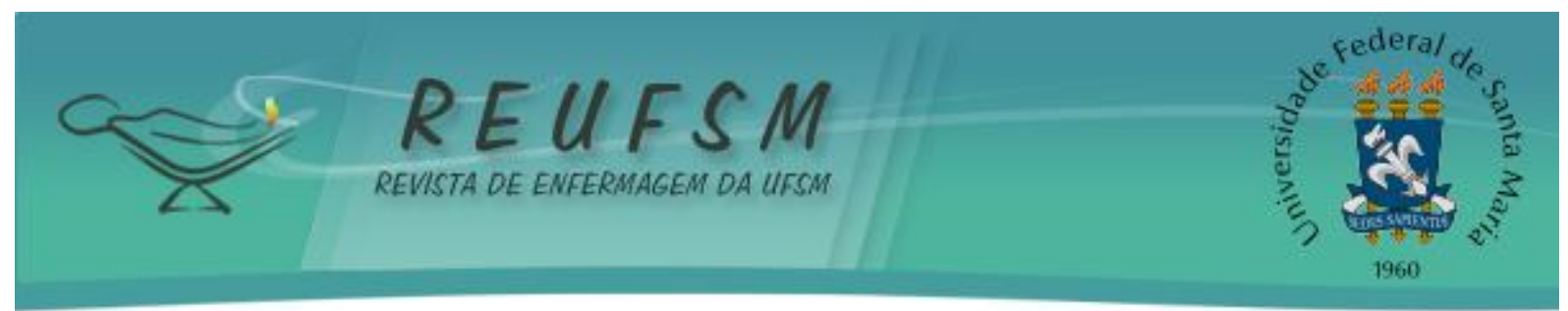

fatores intensificam o abuso ou mesmo a dependência de substâncias psicoativas já utilizadas. Estudo corrobora esse achado e revela que a perda de vínculo familiar e a vivência da violência quotidiana são fatores que elevam o sofrimento mental. ${ }^{22}$

E aí, entrei num vazio. Entrei num vazio mesmo, entrei em depressão, aquela coisa. Eu já era um alcoólatra. (E4)

Eu saia com meu carrinho, encontrava três, quatro colegas: "Ô, toma uma aqui", chegava mais pra frente: "Ô, toma outra", daqui a pouco eu estava bebinho. (E5)

A ida para as ruas é uma ruptura não somente da vida social como pessoal, perdem suas identidades, deixam de ser chamados por um nome próprio para serem chamados ou identificados de acordo com características vistas pelos companheiros da rua/sociedade:

Aí passei a mão num carrinho de papelão, trabalhei, fui puxar papelão. De fardado, virei um catador de papelão, e aí, de fardado virei um mendigo e fui dormir na praça com a garrafa. (E6)

[...] já levei nome de vagabundo. Vai trabalhar, vagabundo! Você é forte, você tem possibilidade, você consegue trabalhar ainda. Mas emprego você não acha, ninguém te dá um emprego. (E2)

Os relatos evidenciam que o trabalho é um componente importante para sobreviver nas ruas, porém, mesmo sentindo-se capazes para o trabalho não conseguem emprego e buscam realizar atividades predestinadas aos andarilhos. Contudo, há situações em que para a população estudada, morar na rua pode ser uma opção, aparentemente cruel para alguns, mas, a única saída para outros, pois a falta de emprego os recoloca no universo da mendicância.

Por estarem sem residência fixa e sem casa, todos são iguais, vivenciam situações semelhantes que favorecem a criação de vínculos. Neste espaço, vivenciam laços afetivos inovadores que originam uma família de rua, sem a rigidez de uma família tradicional. ${ }^{9}$

Nesta vivência de trocas, onde ganhar é perder, ou vice e versa, observa-se que a identidade do sujeito mudará de acordo com as alterações ocorridas na sociedade que agora está inserido. Para a sua sobrevivência, é necessária à manutenção de uma identidade, uma noção de totalidade que o leve a fazer convergir a sua imagem às muitas facetas do seu modo de ser e aos muitos papéis que representa em diferentes momentos da sua experiência social. ${ }^{11}$

De tal modo, as falas a seguir evidenciam a tristeza e os sentimentos de estarem no fundo do poço com dor, angústia e humilhação, experimentados quando se vive nas ruas:

Vivendo nas ruas, quem se sente feliz? [risada]. Não é fácil! (E7)

Tem muita gente que fala, chegar nas ruas é o fundo do poço, é o fundo do buraco. A rua é um pouquinho pior que uma caidinha no poço, um pouquinho pior! (E3)

$\mathrm{Na}$ vivência como morador de rua percebe-se nos relatos a experiência da condição de sub-humano. A literatura relata que o afastamento destas pessoas da condição de ser 


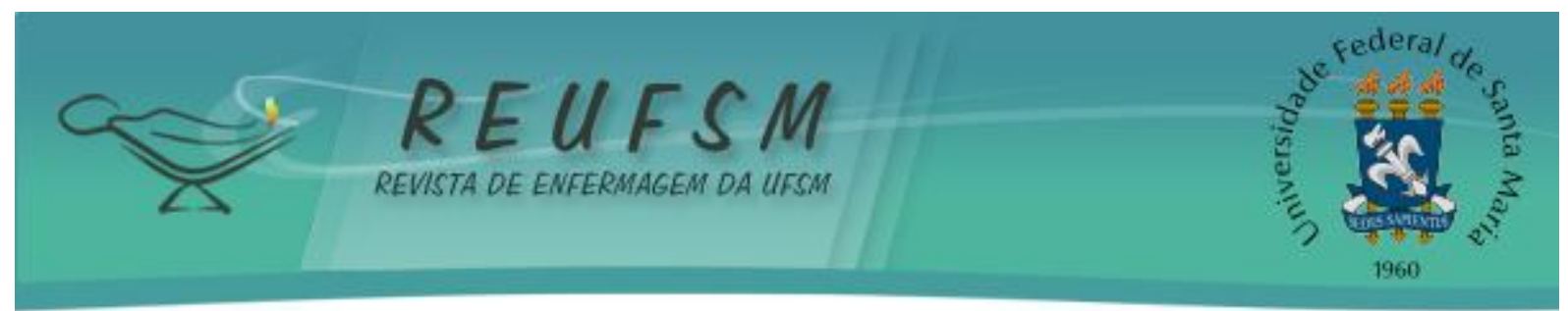

humano é reforçado nos meios de comunicação em notícias que acusam, humilham e estigmatizam a ponto de ocasionar a perda de seus direitos sociais e a própria dignidade. ${ }^{23}$

0 desligamento desses sujeitos do emprego, amigos e, principalmente, de suas famílias, faz com que se sintam como elementos segregados, portadores de uma identidade atrofiada, e tal fato repercute em diversos aspectos de sua vida. ${ }^{24}$

A falta de perspectiva para essas pessoas, principalmente, a dificuldade de encontrar um emprego formal, faz com que aceitem sua condição de morador de rua:

Se eu arrumar um trabalho, que seja registrado pelo menos, para ganhar o suficiente para ajudar a casa e guardar um pouquinho para mim [...] Por que se amanhã a casa fecha, eu vou para onde? Vou voltar para rua, entendeu? (E8)

Observa-se nesse discurso a marca da cultura capitalista, ter um trabalho parece fundamentar o fato. Estudo relata que, ao determinar o ingresso do indivíduo nesta categoria de morador de rua, a pressão da estrutura social e econômica condiciona à formação de uma nova identidade, a de mendigo, o que leva a não se sentir completamente humano. ${ }^{19}$

Esse fenômeno, como um ciclo que constitui um processo de perda da identidade é marcado pelo ritual do documento extraviado (tirar novos documentos e tornar a perdêlos) e contém simbolicamente a tentativa reiterada de adentrar as portas da cidadania que resgataria sua identidade perdida. ${ }^{12}$

\section{0 que passou não volta mais}

Nos depoimentos, de formas estereotipadas, deparamos com a dificuldade do morador de rua em enfrentar sua condição, sua nova identidade:

Voltar que jeito? [risada] Já passou [risada]. O que passou não volta mais. Não gosto muito de falar dela [...] É ruim lembrar o passado. [...] relembra algumas coisas ruins. (E7)

E agora, [risada], olho para mim mesmo e falo: o que é que eu fui fazer? Mas não adianta chorar o leite derramado. (E6)

Esses relatos mostram a dificuldade de falarem de si e de seu passado. Evidenciam desconforto ao confrontarem com a sociedade para qual não mais existem, mas que um dia existiram como trabalhadores, como cidadãos e provedores de famílias.

$\mathrm{Na}$ busca de novas formas de sobrevivência, desenvolvem um mecanismo psíquico compensatório em relação às perdas, usam recursos até então ignorados e assimilam novas formas de organização que permitam a satisfação das necessidades e a superação dos obstáculos que a nova sociedade apresenta. ${ }^{1}$

A busca de identidade nos limites marginais da sociedade pode revelar a necessidade de ora se misturar e ora se distinguir dos diferentes circuitos que se entrecruzam nas ruas, como da pobreza, das relações familiares, da delinquência, da violência e do trabalho desqualificado. Ou mesmo, procuram negar ou distanciar deste contexto quando têm necessidade de utilizarem instrumentos voltados a essa população. ${ }^{25}$

O período de adaptação nas ruas é marcado pelo processo de exclusão social de suas famílias, pelo uso de drogas e vivência de situações de extrema violência, que fazem parte de um passado que preferem não lembrar. ${ }^{24}$ 


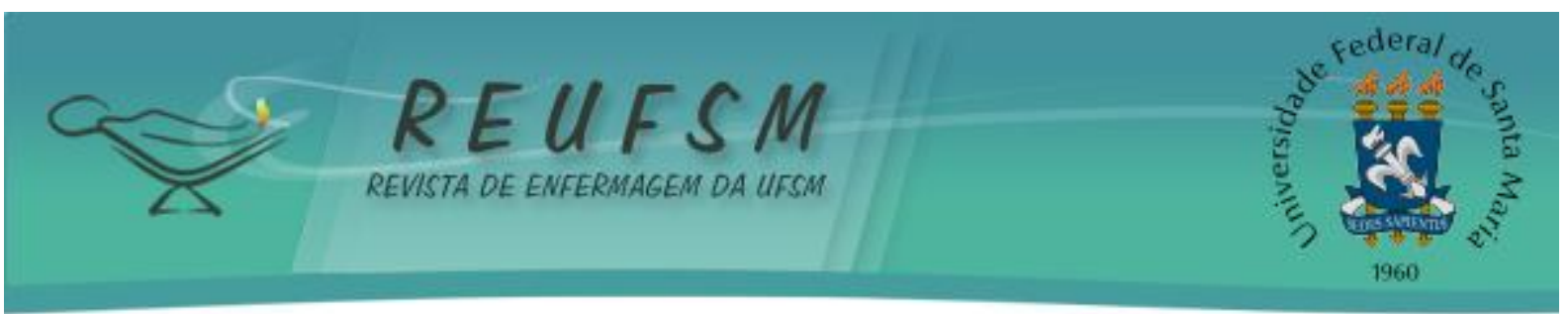

Por esta razão, falar da identidade anterior, da família, é relembrar uma vida longínqua que causa sentimentos de angústia:

É a noite que eu tenho mais saudade de tudo, da minha família... Eu estou voltando ao passado, me dói, machuca muito, mas eu vou voltar $[\ldots](\mathrm{E} 3)$

Eu estou evitando porque é uma ferida que não cicatrizou ainda entendeu? É uma ferida que ainda me machuca. (E8)

A lembrança remete à nostalgia ou, pode-se ainda dizer, a saudade ou até mesmo melancolia ao pensar que algum dia já foi aceito e bem visto pela sociedade, fica marcada em suas mentes.

Esses depoimentos apontam que o morador não esquece quem foi, parece que ter sido alguém em algum momento de sua vida está sempre presente por mais que tente esquecer. A maneira que o morador de rua encontra para se livrar da imagem de si mesmo é negar a sua prática e seu grupo social, buscando, em nível da representação, identificarse com os papéis que agora terá que conviver. ${ }^{12}$ Uma vez que, para construir novos papéis sociais será necessário gerenciar os conflitos internos e reestruturar o sistema familiar.

Para os ex-moradores de rua estudados, suas novas vidas representam, por um lado, o afastamento dos laços familiares, por outro, a família é mantida, simbolicamente, como uma referência à distância.

No contexto brasileiro, no qual a família é considerada unidade imprescindível, ficar sem lugar para morar, estar na rua, é perder vínculo familiar. ${ }^{26}$ Para resgatar os vínculos familiares, torna-se imprescindível o trabalho terapêutico voltado para a comunicação e reflexão sobre as situações de vulnerabilidade, como o abuso de drogas, violência e alcoolismo. ${ }^{3}$ Entretanto, retornar à família não assegura acréscimo na qualidade de vida, pois se relaciona diretamente às expectativas e sentidos atribuídos por cada um, influenciados por crenças e valores individuais construídos ao longo da existência. ${ }^{27}$

\section{CONSIDERAÇÕES FINAIS}

Esse estudo provoca reflexões sobre os valores relacionados às desigualdades, intolerância e injustiça social. Insere novas contemplações nos valores contidos nos sentidos das vivências, na compreensão da relação existente entre os diferentes segmentos da sociedade e os significados de ser ex-morador de rua.

A vivência desses homens mostrou que o processo de ir morar na rua ocasiona a perda da identidade pessoal e sociocultural, e a construção de uma nova identidade espelhada pelo contexto social que ora habitam. Na busca da sobrevivência, experimentam a mendicância com sentimentos de vergonha.

$\mathrm{Na}$ tentativa de retorno ao lar/sociedade antiga demonstram temor a um passado que preferem não recordar, precisam experimentar um processo inverso àquele que vivenciado ao irem para as ruas, necessitam resgatar a identidade perdida e, finalmente, reconstituir os laços afetivos consigo próprio e com seus familiares. Todavia, essa pesquisa aponta que o retorno é vivenciado de forma ambivalente.

A busca de identidade de ex-moradores de rua é um processo que envolve muitas etapas; não basta dar-lhes moradia, é preciso resgatá-los enquanto cidadãos e reinseri-los na sociedade de forma gradual, aonde aos poucos irão se reconhecer enquanto indivíduos nesse novo contexto. 


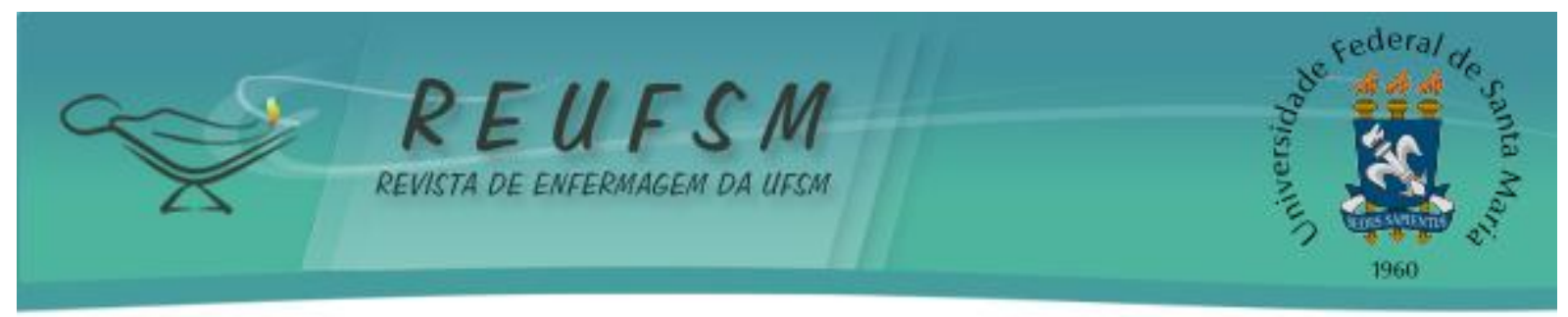

O morar na rua é vivido como uma marca e o processo de retorno precisa ser a cada momento (re)contextualizado e (re)significado para poder ser reconstruído sobre novas bases. Os recursos a serem disponibilizados a essa população precisam circunscrever ações em termos sociais e psicológicos além de questões ligadas a infraestrutura.

Esse estudo reafirma a necessidade das instituições que albergam pessoas desenvolvam, por meio das equipes de multiprofissionais de saúde, competências para o cuidado dessa parcela da população. Além disso, se faz necessário repensar as políticas que servem de diretrizes para o trabalho com as pessoas em situação de rua para que os serviços tenham condições de equacionar ações e estratégias de intervenção que auxiliem no acolhimento das reais demandas dessa comunidade.

Embora esse estudo esteja circunscrito a um contexto de pessoas específicas, apontou para a necessidade de que novos trabalhos sejam desenvolvidos para que se possa cada vez mais conhecer as peculiaridades desse segmento social.

Este estudo possui limitações, pois abordou a população de ex-moradores de rua acolhida por instituições de abrigo devido à imposição de riscos ao entrevistador e entrevistado caso a pesquisa fosse desenvolvida nas ruas. Considera-se, também, o número restrito de instituições que abrigam essa população e a pouca permanência nessas instituições, visto que os que residem por mais tempo, geralmente, estão limitados por razões físicas e clínicas.

\section{REFERÊNCIAS}

1. Rosa AS, Cavicchioli MGS, Brêtas ACP. Health-sickness-care process and the street population. Rev Latinoam Enferm [Internet]. 2005 ago [acesso em 2008 set 8];13(4):57682. Disponível em: http://www.scielo.br/pdf/rlae/v13n4/v13n4a17.pdf.

2. Silva FP, Frazão IS, Linhares FMP. Práticas de saúde das equipes dos Consultórios de Rua. Cad Saúde Pública [Internet]. 2014 abr [acesso em 2014 dez 13];30(4):805-14. Disponível em: http://www.scielo.br/pdf/csp/v30n4/0102-311X-csp-30-4-0805.pdf.

3. Silva HS, Gutierrez BAO. Dimensões da qualidade de vida de idosos moradores de rua do município de São Paulo. Saúde Soc [Internet]. 2013 mar [acesso em 2014 dez 14];22(1):148-59.

Disponível

http: / /www.scielo.br/scielo.php?script=sci_arttext\&pid=S0104-

$12902013000100014 \&$ lng=pt\&nrm=iso.

4. Brandão BHB. Habitando na rua: avaliação pós-ocupação e saúde pública em equipamentos urbanos para a população de rua [dissertação]. São Paulo (SP): Universidade de São Paulo; 2004 [acesso em 2008 set 8]. Disponível em: http://www.teses.usp.br/teses/disponiveis/6/6136/tde-05072006-082652/pt-br.php.

5. Brasil. Ministério do Desenvolvimento Social e de Combate à Fome. Pesquisa Nacional sobre a População em Situação de Rua [Internet]. Brasília: Ministério do Desenvolvimento Social e de Combate à Fome; 2008 [acesso em 2010 fev 26]. Disponível em: http://www.mds.gov.br/backup/arquivos/sumario_executivo_pop_rua.pdf.

6. Serrano CEG. Eu mendigo: alguns discursos da mendicância na cidade de São Paulo [tese]. São Paulo: USP, Insituto de Psicologia; 2004 [acesso em 2010 jan 15]. Disponível em: http://www.teses.usp.br/teses/disponiveis/47/47131/tde-20092004-153545/ptbr.php.

7. Aguiar MM, Iriart JAB. Significados e práticas de saúde e doença entre a população em situação de Rua em Salvador, Bahia, Brasil. Cad Saúde Pública [Internet]. 2012 jan [acesso em 2013 ago 7];28(1):115-24. Disponível em: http://www.scielo.br/pdf/csp/v28n1/12.pdf. 


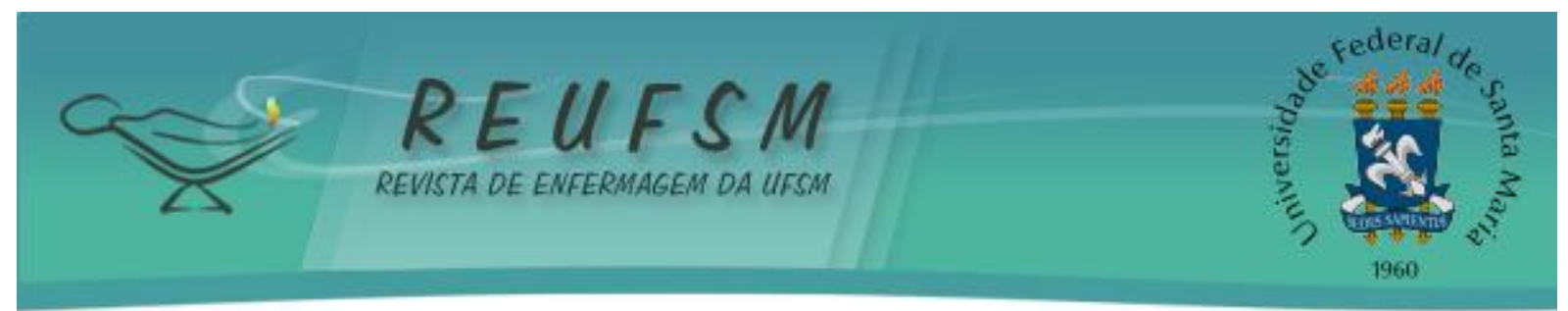

8. Grangeiro A, Holcman MM, Onaga ET, Alencar HDR, Placco ALN, Teixeira PR. Prevalência e vulnerabilidade à infecção pelo HIV de moradores de rua em São Paulo, SP. Rev Saúde Pública [Internet]. 2012 ago [acesso em 2014 dez 14];46(4):674-84. Disponível em: http: / / www.scielosp.org/scielo.php?script=sci_arttext\&pid=S0034-

$89102012000400012 \& \operatorname{lng}=$ en .

9. Porto L, Backes DS, Diefenbach GDF, Costenaro RGS, Rangel RF, Lucio DBM, Martins ESR. Viver saudável: significado para os moradores de rua do município de Santa Maria. Rev Enferm UFSM [Internet]. 2012 jan/abr [acesso em 2014 jan 8];2(1):59-66 Disponível em: http://cascavel.ufsm.br/revistas/ojs-2.2.2/index.php/reufsm/article/view/4413/3127.

10. Fundação Instituto de Pesquisas Econômicas (Fipe). Pesquisas identificam perfil dos moradores de rua de São Paulo [Internet]. 2008 [acesso em 2008 maio 25]. Disponível em: http://www..fipe.com.br/web/home/noticia.aspx?c=37.

11. Fernandes KR, Zanelli JC. O processo de construção e reconstrução das identidades dos indivíduos nas organizações. RAC [Internet]. 2006 jan/mar [acesso em 2009 jun 30];10(1):55-72. Disponível em: http://www.scielo.br/pdf/rac/v10n1/a04.pdf.

12. Prefeitura de São Paulo. População de rua: quem é, como vive e como é vista. São Paulo: Hucitec; 1992.

13. Turato ER. Métodos qualitativos e quantitativos na área da saúde: definições, diferenças e seus objetos de pesquisa. Rev Saúde Pública [Internet]. 2005 jun [acesso em 2009 mar 10];39(3):507-14. Disponível em: www.scielo.br/pdf/rsp/v39n3/24808.pdf.

14. Medeiros KMC, Mariz CL. Toca de Assis em crise: uma análise dos discursos dos que permaneceram na comunidade. Relig Soc [Internet]. 2013 jul/dez [acesso em $2014 \mathrm{dez}$ 12];33(2):141-73. Disponível em: http://www.scielo.br/pdf/rs/v33n2/08.pdf.

15. Gonçalves DM, Stein AT, Kapczinski F. Avaliação de desempenho do Self-Reporting Questionnaire como instrumento de rastreamento psiquiátrico: um estudo comparativo com o Structured Clinical Interview for DSM-IV-TR. Cad Saúde Pública [Internet]. $2008 \mathrm{fev}$ [acesso em 2009 mar 10];24(2):380-90. Disponível em: http://www.scielosp.org/pdf/csp/v24n2/16.pdf.

16. Fontanella BJB, Ricas J, Turato ER. Amostragem por saturação em pesquisas qualitativas em saúde: contribuições teóricas. Cad Saúde Pública [Internet]. 2008 jan [acesso em 2009 abr 5];24(1):17-27. Disponível em: www.scielo.br/pdf/csp/v24n1/02.pdf.

17. Minayo MCS. O desafio do conhecimento: pesquisa qualitativa em saúde. $10^{\mathrm{a}}$ ed. São Paulo: Hucitec; 2006.

18. Gabbard GO. Principais modalidades: psicanalítica/psicodinâmica. In: Gabbard GO, Beck JS, Holmes J. Compêndio de psicoterapia de Oxford. Porto Alegre: Artmed; 2007. p. 14-29.

19. Mattos RM, Ferreira RF. Quem vocês pensam que (elas) são? - representações sobre as pessoas em situação de rua. Psicol Soc [Internet]. 2004 maio/ago [acesso em 2007 mar 20];16(2):47-58. Disponível em http://www.scielo.br/pdf/psoc/v16n2/a07v16n2.pdf.

20. Alvarez AMS, Alvarenga AT, Sommerman A, Della Rina SCSA. Histórias de vida de moradores de rua, situações de exclusão e encontros transformadores. Saúde Soc [Internet]. $2009 \mathrm{abr} /$ jun [acesso em 2010 out 7];18(2):259-72. Disponível em: http://www.scielo.br/pdf/sausoc/v18n2/09.pdf.

21. Alvarez AMS, Alvarenga AT, Sommerman A, Della Rina SCSA. Pesquisa-ação-formação 


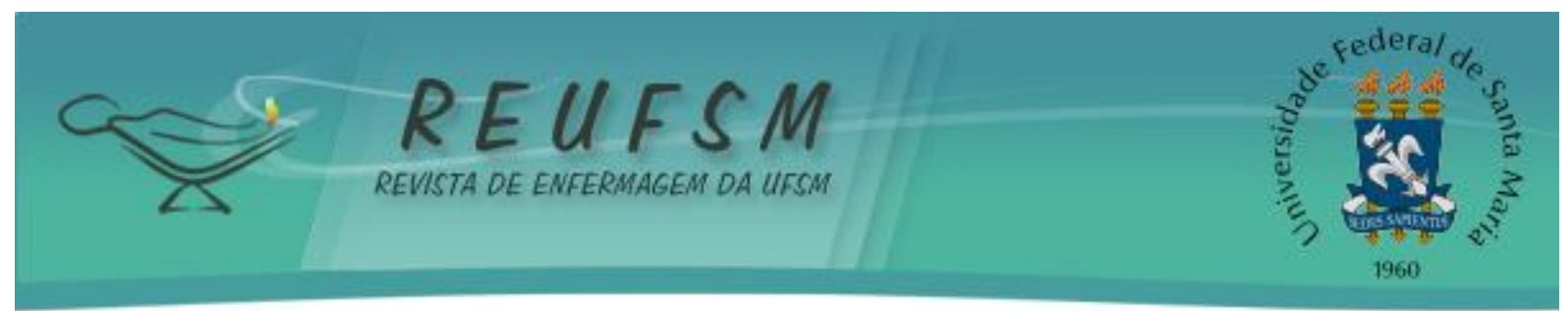

inter e transdisciplinar com pessoas envolvidas com a questão do morador de rua. Saúde Soc [Internet]. 2011 abr/jun [acesso em 2014 jan 8];20(2):300-13. Disponível em: www.revistas.usp.br/sausoc/article/download/29792/31674.

22. Botti NCL, Castro CG, Silva AK, Silva MF, Oliveira LC, Castro ACHOA, et al. Avaliação da ocorrência de transtornos mentais comuns entre a população de rua de Belo Horizonte. Barbarói [Internet]. 2010 ago/dez [acesso em 2014 dez 14];(33):178-93. Disponível em: http://online.unisc.br/seer/index.php/barbaroi/article/viewFile/1583/1318.

23. Almeida DAC. Morador de rua: da questão social a questão midiática. Puçá: Rev de Comunicação e Cultura na Amazônia [Internet]. 2011 jan/jun. [acesso em 2014 dez 14];1(1):77102. Disponível em: http://revistaadmmade.estacio.br/index.php/puca/article/view/95/92.

24. Gontijo DT, Medeiros M. "Tava morta e revivi": significado de maternidade para adolescentes com experiência de vida nas ruas. Cad Saúde Pública [Internet]. $2008 \mathrm{fev}$ [acesso em 2009 jan 20];24(2):469-72. Disponível em: http://www.scielo.br/pdf/csp/v24n2/25.pdf.

25. Varanda W, Adorno RCF. Descartáveis urbanos: discutindo a complexidade da população de rua e o desafio para políticas de saúde. Saúde Soc [Internet]. 2004 jan/abr [acesso em 2007 set 15];13(1):56-69. Disponível em: http://www.scielo.br/pdf/sausoc/v13n1/07.pdf.

26. Fernandes FSL, Raizer MV, Brêtas ACP. Old, poor and out on the street: on the road to exclusion. Rev Latinoam Enferm [Internet]. 2007 set/out [acesso em 2009 jun 30];15(N Esp):755-61. Disponível em: http://www.scielo.br/pdf/rlae/v15nspe/pt_06.pdf.

27. Souza RG, Lovisi GM. Avaliação de déficits cognitivos em moradores com mais de 65 anos de um albergue público. Rev Psiq Clín [Internet]. 2007 out [acesso em 2009 jun 30];34(5):205-9. Disponível em: http://www.scielo.br/pdf/rpc/v34n5/a01v34n5.pdf.

Data de recebimento: 19/02/2014

Data de aceite: 20/02/2015

Contato com autor responsável: Milene Pescatori Packer

Endereço postal: Rua Joaquim de Paula Leite, 85 - Solar do Itamaracá - Indaiatuba-SP, CEP: $13333-400$

E-mail: packer_mi@hotmail.com 